\title{
PLANTÃO PSICOLÓGICO: De frente com o inesperado
}

\author{
Psychological duty: Face to face with the unexpected one
}

\author{
Priscila Barros Chaves ${ }^{a}$, Wilma Magaldi Henriques ${ }^{b}$ \\ a Psicóloga pelo Curso de Psicologia da Universidade de Mogi das Cruzes. Caraguatatuba, SP - Brasil, e-mail:priscilabch@gmail.com \\ b Supervisora do Plantão Psicológico no Curso de Psicologia da Universidade de Mogi das Cruzes. Mestre em Psicologia Clínica \\ pela PUCCAMP e Doutora em Psicologia pela USP, Curitiba, PR - Brasil, e-mail: magaldihenriques@ig.com.br
}

\begin{abstract}
Resumo
O presente artigo nos traz algumas experiências do estágio em Plantão Psicológico na ClínicaEscola de Psicologia da Universidade de Mogi das Cruzes (SP), realizado por mim ${ }^{1}$ durante o $9^{\circ}$ semestre do curso de graduação. O Plantão Psicológico pode ser definido como um tipo de intervenção psicológica, que acolhe a pessoa no exato momento de sua necessidade, ajudando-a a lidar melhor com seus recursos e limites, na medida em que o plantonista neste caso, estagiário, coloca-se disponível a acolher a experiência deste paciente em determinada situação. Isso significa lidar com o inesperado, com o que é trazido no exato momento do atendimento, onde angústias são intensamente vivenciadas de forma recíproca. Vale lembrar que são necessárias reflexões e reconfigurações acerca das práticas psicológicas desenvolvidas em clínicas-escola e em instituições, além de se tornar urgente abandonar concepções tradicionais no atendimento clínico para que, assim, abra-se mais espaço para o Plantão Psicológico.
\end{abstract}

Palavras-chave: Plantão psicológico; Acolher; Inesperado.

1 Embora esse texto seja de autoria múltipla, a experiência aqui relatada refere-se ao Estágio em Plantão Psicológico vivenciado pela primeira autora e supervisionado pela segunda. 


\begin{abstract}
The present article brings to us some experiences of the period of training in Psychological duty in the of Psychology of the Universidade de Mogi das Cruzes/SP, it was accomplished by me during $9^{\circ}$ semester of the graduation course. The Psychological duty can be set like a type of intervention psychological where the person is host in the exact moment of its necessity; it helps the one handle better with its resources and boundaries; to the long that the trainee puts it the disposition, ready to host the experience of this patient in some situation means deal with the unexpected one, with what is carried at the exact moment of the enquiry where anguishes are vividly lived in reciprocal way. It is good to remember reflections and re -configurations are required around of the practices psychological developed in clinic-school and in institutions, besides to become urgent. Quit traditional conceptions during the clinical enquiry to open up more air to the Psychological duty.
\end{abstract}

Keywords: Psychological duty; To welcome; Unexpected.

\section{INTRODUÇÃO}

\section{Revisitando contextos sobre o plantãopsicológico}

Por meio de experiência em Plantão Psicológico junto à Clínica de Psicologia da Universidade de Mogi das Cruzes/SP, além de alguns plantões realizados em Posto de Saúde na mesma cidade, pude experienciar, como alunaestagiária do $9^{\circ}$ período de Psicologia, a importância do plantão na vida das pessoas.

O ser humano de nossos dias vem vivendo uma realidade que, progressivamente e quase que inevitavelmente, causa-lhe um estado de tensão, de desgaste de seu organismo como um todo. Os estados de depressão, de pânico, estresse, angústia, insegurança, medo, ansiedade e tantos outros produzidos pelo modo de vida de nossas cidades e grupos sociais vêm se mostrando, a cada dia, mais intensos e freqüentes.

A instalação do serviço de plantão psicológico foi também uma novidade para a psicologia clínica. Teve seu início nos anos 60, quando Rachel Rosemberg o constituiu, no Serviço de Aconselhamento Psicológico (SAP) do Instituto de Psicologia da USP (Ipusp), tendo como referência a Abordagem Centrada na Pessoa de Carl Rogers.

O Plantão Psicológico é um tipo de intervenção psicológica que acolhe a pessoa no exato momento de sua necessidade, ajudando-a a lidar melhor com seus recursos e limites. Segundo Mahfoud (1987, p. 76), "na medida em que \{o plantonista\} se coloca disponível a acolher a experiência do paciente em determinada situação, ao invés de enfocar o seu problema [...]. A palavra plantão está associada a certo tipo de serviço, exercido por profissionais que se mantêm à disposição de quaisquer pessoas que deles necessitem, em períodos de tempo previamente determinados e ininterruptos". Do ponto de vista da instituição, o atendimento de plantão pede uma sistematicidade do serviço oferecido. Do profissional, esse sistema pede uma disponibilidade para se defrontar com o não planejado e com a possibilidade (nem um pouco remota) de que o encontro com o cliente seja único. E ainda, da perspectiva do cliente, significa um ponto de referência para algum momento de necessidade (Mahfoud, 1987).

No plantão psicológico, cujo objetivo é $\mathrm{o}$ atendimento emergencial à demanda, tem-se uma proposta muito semelhante, embora esta prática tenha se desenvolvido a partir de um contexto, o de aconselhamento psicológico, "solo para as tensões da existência do homem em situação de vida no mundo com os outros, ou seja, das relações interpessoais" (Morato, 1999, p. 83) nem sempre visto como atividade clínica.

Tal prática inspira-se na proposta de atendimento clínico breve, fora dos moldes consultoriais, conforme proposta de Morato (1999) e, como lembra Cury (1999), viabilizam um atendimento de tipo emergencial e que funciona sem necessidade de agendamento, destinado a pessoas que a ele recorrem, espontaneamente, em busca de ajuda para problemas de natureza emocional. Como afirma 
Schmidt (1999), a entrevista do plantão visa facilitar que o cliente clarifique a natureza de seu sofrimento e de sua demanda por ajuda. O tipo de elaboração e o grau de elaboração que são alcançados nesta primeira entrevista são os critérios norteadores dos desdobramentos possíveis deste encontro inicial. O que nos mostra Rogers (1961) sobre as relações nas quais pelo menos uma das partes (plantonista) procura promover na outra o crescimento, o desenvolvimento, a maturidade, um melhor funcionamento e uma maior capacidade de enfrentar a vida. O outro, neste sentido, pode ser quer um indivíduo, quer um grupo. Por outras palavras, a relação de ajuda durante os plantões pode ser definida como uma situação na qual um dos participantes procura promover numa ou noutra parte, ou em ambas uma maior apreciação, uma maior expressão e uma utilização funcional dos recursos internos latentes do indivíduo.

Citarei alguns trabalhos que achei bastante interessantes, como o realizado sobre Transgressão e Juventude encarcerada em unidades de internação da FEBEM/SP (Aun, 2006), que tinham o Plantão Psicológico como uma modalidade de prática clínica oferecida a adolescentes e funcionários de seis unidades da FEBEM/SP, localizadas em dois complexos da Capital. Também foi disponibilizada por mais de três anos pelo Laboratório de Estudos e Prática em Psicologia e Fenomenologia Existencial (LEFE) do Instituto de Psicologia da Universidade de São Paulo (IP-USP), como uma clínica contextualizada propriamente no cotidiano da Instituição. Uma direção pertinente ao trabalho realizado pode ser expressa como um acompanhar o sujeito em sua busca por sentido de existência, na compreensão de um sofrimento, embora sem a garantia de seu alívio ou de um viver somente na experiência de prazer imediato e presente. Assim como não se oferecem garantias, a priori, de um determinado fim, pode-se também considerar que a busca por sentido não se esgota num total esclarecimento por meio da experiência vivenciada em Plantão Psicológico, mas é sempre retomada como um conduzir-se pela existência, pautada no cuidado e nas possibilidades de projeto de bem-estar (Almeida, 1999).

Também o trabalho realizado a partir de depoimentos de alunos de um curso de aperfeiçoamento em psicodiagnóstico colaborativo, oferecido no Serviço de Aconselhamento Psicológico da USP (Interlocuções entre o plantão psicológico e o psicodiagnóstico colaborativo), onde habitualmente são desenvolvidas as atividades referentes ao plantão psicológico, e o trabalho teve como objetivo focalizar as possíveis interlocuções entre estas práticas, assim como sua contribuição para o acolhimento do cliente e a formação do aluno. A investigação preliminar permite dizer que profissionais que têm contato com a prática do Plantão Psicológico e que entram em contato com o psicodiagnóstico colaborativo, na abordagem fenomenológico-existencial, dão-se conta da oposição à postura tradicional em relação a conhecimento e verdade já que o enfoque teórico está orientado na mesma direção (fenomenológicoexistencial), valorizando a relação com o outro, focalizando a compreensão do que esteja acontecendo consigo próprio e com o outro (Yehia, 2004).

A implantação do Plantão Psicológico também foi realizada em escolas. Como nos mostra Mahfoud (1999, p. 30-31, 53), "construir um espaço para o aluno ou pessoa", além de ser "um método de presença entre alunos e professores", com o objetivo de "possibilitar aos alunos um espaço e oportunidade de se cuidar, de estarem atentos ao que é realmente importante para eles naquele momento e então se posicionarem diante disso". Esse trabalho constituise em uma pesquisa-ação que desvelou temas existencialmente relevantes para jovens, tais como "preocupação em conseqüências de ações ou decisões passadas", "dificuldades em fazer escolhas", "elaboração de perdas", "arrependimento e culpa", "sexualidade", "dificuldades com a escola", "busca de reconhecimento", "desconfiança nos relacionamentos", "insatisfação nos relacionamentos com a família", "falta de correspondência nos relacionamentos amorosos", "falta de reciprocidade nos relacionamentos já estabelecidos". Essas categorias dirigem o olhar para os adolescentes como pessoas e não como estereótipos ou meramente seres impessoais que devem aprender apenas conteúdos escolares. São pessoas situadas, diante do desafio de aprender e estar mais aberto ao mundo.

\section{DESCORTINANDO CENÁRIOS}

No primeiro momento da supervisão na própria Universidade realizada semanalmente com os estagiários e com a professora supervisora, confesso que fiquei um pouco apreensiva, pois 
lidaria diretamente com o inesperado, com a emergência que o paciente me trouxesse, pois as pessoas que procuram o plantão estão vivendo questões e problemas que surgem naquele momento como algo que chegou ao limite e necessita de cuidado, ou ainda estão passando por mudanças drásticas e procuram orientação e o reencontro com seu equilíbrio anterior, é o confiar em abrir sua vida íntima ao outro que o escuta. Daí o medo, pois a minha atuação como terapeuta (estagiária) não vinha de um modelo predefinido, ou seja, nada planejado, como nos estágios anteriores (referindo-se aos modelos terapêuticos tradicionais) apesar de concordar que não há duas terapias iguais e a cada encontro uma nova descoberta, um novo significado e o que o paciente espera é que encontre alguém para ouvi-lo e ajudá-lo a suportar e buscar saídas para seu sofrimento a fim de aliviar determinada angústia. Como nos traz Sapienza (2004), este trabalho é de pensamento, faz essencialmente uso de linguagem, mas bem poderia ser chamado de artesanal, pois paciente e terapeuta pensam e sentem juntos.

Segundo Leloup (2001), escutar alguém implica, em certo sentido, uma abdicação de si, é importante perceber que sentido tem o comunicado para quem o transmite. Acolher a palavra do outro, desde a mais corpórea até a ainda não pronunciada. Essa acolhida também é, ao mesmo tempo, física e espiritual, para considerar o homem em sua totalidade.

Cena I - Mas já no primeiro plantão, pude me deixar levar por aquele momento, que para mim foi prazeroso, apenas pelo fato de poder dar chance a uma pessoa de falar sobre seus sentimentos, seus medos, enfim, toda a minha ansiedade foi indo embora... fui me aproximando do que estava sendo revelado a mim... "o caso de uma jovem de 26 anos que simplesmente não sentia vontade de viver, por se sentir gorda demais e por isso não conseguia um namorado, nem se sentia amada" [...] o modo como ia colocando tudo isso para fora me fez perceber como o seu corpo também estava angustiado, a sua comunicação não-verbal era muito bem explorada, sentava-se de forma curvada na cadeira, ombros caídos, mal conseguia me olhar nos olhos[...]. Ao final de 50 minutos, a diferença estava visível, pois ela saiu da sala menos angustiada, sorrindo, não que todos os medos tivessem ido embora, mas pelo menos o fato de colocá-los para fora a ajudou a lidar melhor com esses conflitos que tanto a distanciavam das pessoas e talvez de si mesma. E então eu me pergunto o que efetivamente acontece nesses encontros? Parece-me que a possibilidade de narrar a própria história possibilita que a pessoa se veja no seu discurso e se reconstrua a partir de si mesma e do outro (o plantonista) que a acolhe nas suas semelhanças, estranhezas e nas suas diferenças.

Cena II - Segundo Rogers (1987), se atendermos a complexidade da vida humana com olhar justo, temos que reconhecer que é altamente improvável que possamos reorganizar a estrutura da vida de um indivíduo. Se pudermos reconhecer esse limite e nos obtivermos de desempenhar o papel de Deus, poderemos oferecer um tipo muito precioso de ajuda, de esclarecimento, mesmo num curto espaço de tempo. Podemos permitir ao cliente que exprima seus problemas e sentimentos de forma livre, e deixá-lo com o reconhecimento das questões que enfrenta. Será que como plantonista ofereço essa ajuda?! Será que estou acolhendo as angústias, estando aberta ao encontro com o outro?!

Pensando no conhecimento tácito, que segundo Figueiredo (1996) seria incorporado às capacidades afetivas, cognitivas, motoras e verbais de um sujeito (tácito é calado, silencioso). A dificuldade de "fazer falar o tácito" advém do fato de que o conhecimento pessoal existe em um plano de experiência em que sujeito e objeto ainda não se constituem com entidades relativamente independentes uma da outra. Existe também o conhecimento explícito, o conhecimento que se torna disponível na forma de sistemas de representação, como é o caso de uma teoria. O que me faz pensar que o conhecimento tácito então fala mais alto e o explícito ilumina o fenômeno para uma melhor compreensão no momento do plantão.

Existe uma troca intersubjetiva entre a pessoa que traz a história e o plantonista. Pois o papel de plantonista pode ser bastante relacionado ao de educador naquele momento tão único. A compreensão está em contínua elaboração, posta em linguagem, buscando formular a situação de estar no mundo como educador. Brandão (1982) mostra-nos [...] que qualquer pensar consciente do educador sobre o seu trabalho, só pode ser o pensar crítico que reveja e renove a sua prática todos os dias [...] além do mais, a educação é um acontecimento que se recria a cada dia. Portanto, 
entende-se que a linguagem não cumpre apenas a função comunicativa, mas constitui-se na explicitação da compreensão do mundo e de si mesmo, e isto é válido para ambos que participam da entrevista. "A linguagem é o pronunciamento do discurso", diz-nos Heidegger (1988, p. 219), e este é constitutivo da existência humana, assim como a compreensão e a disposição. "O ser humano é falante", diz Nunes (2002, p. 20) e "O discurso é a articulação dessa compreensibilidade" (Heidegger, 1988, p. 219), sendo a escuta e o silêncio possibilidades intrínsecas da linguagem. $\mathrm{O}$ discurso se comunica naquilo sobre o que discorre e que constitui o que Heidegger (1988, p. 220) chama de "o dito dos desejos, das perguntas, dos pronunciamentos". Como assinala Amatuzzi (1989, p. 19), "ao falar, sempre falo algo, mas também falo a alguém, com uma intenção e o defino nesse ato em relação a mim e ainda, ao falar eu me falo". Vemos assim que a fala é a produção de sentidos. Assim, o paciente busca-se em sua fala, observa-se e escuta-se... a forma pela qual suas angústias vão sendo colocadas para fora de modo a trazer talvez um pouco mais de tranqüilidade naquele determinado momento do plantão, pois a busca será constante e inesgotável.

Cabe ao plantonista no momento do atendimento ouvir o que está sendo dito pelo seu paciente. E é importante ressaltar que ouvir, segundo Rosenthal (1999), pode sugerir uma atitude passiva, mas não é. Ouvir implica acompanhar, ou seja, estar atento, presente. Significa ter concentração e não estar dispersivo como quem ouve um eco (quando as palavras tornam-se ocas). Isso aumentará a proximidade do paciente tanto dos seus sentimentos, quanto da liberação deles. A confiança neste momento será de grande valia para ambas as partes.

Rogers (1961) trouxe-nos que o terapeuta, no momento da terapia, considera seu paciente como uma pessoa incondicionalmente válida, sejam quais forem os seus comportamentos, os seus sentimentos ou a sua condição. O que significa que o terapeuta é autêntico, que não se esconde atrás de uma fachada defensiva, mas que vai ao encontro do paciente com os sentimentos que cai organicamente a experimentar. Significa que o terapeuta é capaz de se abandonar para compreender o seu paciente: que não existem barreiras interiores a impedirem-no de sentir o que ele próprio e o paciente sentem em cada momento da relação e que pode transmitir algo dessa compreensão de empatia ao paciente. Isso significa, por último, que o terapeuta está à vontade ao introduzir-se plenamente na relação com o paciente, sem conhecer de antemão para onde se encaminham satisfeito com o fato de proporcionar um clima que torna possível ao indivíduo a maior liberdade para ele próprio. $\mathrm{O}$ que também ocorre durante os plantões, pois é o momento único em que o plantonista, querendo ou não, aprende a lidar com a sua "ansiedade" de ouvir o que o paciente trás e também lidar com as suas emoções e seus sentimentos particulares. De repente, o que pode ser trazido pode aproximar-se muito de determinado momento da vida do plantonista, algum problema parecido, enfim! Só que cabe a ele, neste momento, deixarse realmente de lado e se dar ao outro.

Cena III - Seria bastante interessante e sem dúvida importante que muitas pessoas, em determinadas circunstâncias da vida, beneficiassem-se com o plantão psicológico, também uma oportunidade de escutar a si mesmos, identificar e reconhecer seus próprios sentimentos, tendo a possibilidade de autodireção, momento em que tiver de enfrentar alguma dificuldade, possibilidade de reformular seus significados sem que para isso tenham que se submeter ao atendimento sistemático, prolongado, como tradicionalmente oferecem as psicoterapias (deixando bem claro que não desmerecendo a elas que são tão importantes quanto). O que as pessoas precisam também é perder um pouco o preconceito e deixar de estigmatizar tanto a imagem do psicólogo, achando que quem procura pelos serviços da psicologia é "louco" ou coisa parecida.

\section{CONSIDERAÇÕES FINAIS}

Os plantões na Clínica-Escola de Psicologia da Universidade de Mogi das Cruzes foram crescendo gradativamente. Acredito até que no início alunos e professores estavam de certa forma desconfortáveis com tal situação, com o "novo" surgindo, afinal não deixava de ser um desafio para eles implantar o plantão psicológico numa clínica-escola onde há mais de 30 anos oferecia somente o tratamento clínico tradicional (psicoterapias). Mas, aos poucos, tudo foi se entrelaçando e os plantões sendo cada vez mais procurados pela 
população, já que em certo momento foi divulgado na mídia, o que aproxima ainda mais as pessoas do que está ocorrendo. Interessante como de repente o número de atendimentos duplicou. No posto de saúde também não foi diferente, pois a procura passou a ser grande.

Penso que o trabalho foi muito bem feito tanto por nós alunos (plantonistas) quanto pelos professores supervisores. No meu caso, uma experiência renovadora, que me trouxe muito de mim, pois em certos momentos me via ali, do outro lado, onde a "possibilidade de suportar as diferenças emergentes no encontro abria para o acolhimento, por um moto contínuo à compreensão a partir da afetação" (Henriques, 2005, p. 147).

Necessárias reflexões e reconfigurações acerca das práticas psicológicas desenvolvidas em clínicas-escola e nas instituições. $\mathrm{Na}$ perspectiva de atendimento à demanda, impõese a necessidade de abandonar certas concepções tradicionais da clínica, abrindo propostas como a de Plantão Psicológico para contemplar as emergências trazidas aos serviços de Psicologia.

É espantoso constatar o quão diminuta é a capacidade das pessoas em admitir a validade do argumento dos outros, embora esta capacidade seja uma das premissas fundamentais e indispensáveis de qualquer comunidade humana. Todos os que têm em vista uma confrontação consigo próprios devem contar sempre com esta dificuldade geral. $\mathrm{Na}$ medida em que o indivíduo não reconheça o valor do outro, nega o direito de existir também ao 'outro' que está em si, e vice-versa. A capacidade de diálogo interior é um dos critérios básicos da objetividade (Jung, 1991, par. 187).

\section{REFERÊNCIAS}

Almeida, F. M. de (1999). Aconselhamento Psicológico numa visão fenomenológicoexistencial: cuidar de ser. In H. T. P., Morato. Aconselhamento psicológico centrado na pessoa: Novos desafios. (pp. 45-60). São Paulo: Casa do Psicólogo.

Amatuzzi, M. M. (1989). O resgate da fala autêntica. Campinas: Papirus.
Aun. A., Morato, H. P., Noguchi, N. F. de C. (2006). Transgressão e Juventude encarcerada: outras versões a partir do plantão psicológico em unidades de internação da FEBEM/SP. Imaginário, 12(12), 35-53.

Brandão, C. R. (Org.). (1982). O educador: Vida e morte. Rio de Janeiro: Graal.

Cury, V. E. (1999). Plantão Psicológico em clínica-escola. In M., Mahfoud. Plantão psicológico: Novos horizontes. (pp. 115133). São Paulo: Companhia Ilimitada.

Figueiredo, L. C. M. (1996). Revisitando as psicologias: Da epistemologia à ética das práticas e discursos psicológicos. Petrópolis: Vozes.

Heidegger, M. (1988). Ser e tempo. Petrópolis: Vozes.

Henriques, W. M. (2005). Supervisão: Lugar mestiço para aprendizagem clínica. São Paulo, Tese de doutorado, Instituto de Psicologia da Universidade de São Paulo, São Paulo.

Jung, C. G. (1991). A dinâmica do inconsciente. O. C. (Vol. 8). Petrópolis: Vozes.

Leloup, J. Y. (2001) Cuidar do ser: Filon e os terapeutas de Alexandria. (6a ed). Petrópolis: Vozes.

Mahfoud, M. (1987). A vivência de um desafio: Plantão psicológico. In R. L., Rosemberg. (Org.). Aconselhamento psicológico centrado na pessoa. São Paulo: E.P.U.

Mahfoud, M. (1999). Plantão psicológico: Novos horizontes. São Paulo: Companhia Ilimitada.

Morato, H. P. T. (1999). Aconselhamento psicológico centrado na pessoa. São Paulo: Casa do Psicólogo.

Nunes, B. (2002). Heidegger \& ser e tempo. Rio de Janeiro: Zahar.

Rogers, C. R. (1961). Tornar-se pessoa. São Paulo: Martins Fontes.

Rogers, C. R. (1987). Psicoterapia e consulta psicológica (Coleção Psicologia e Pedagogia). São Paulo: Martins Fontes. 
Sapienza, B. T. (2004). Conversa sobre terapia. São Paulo: EDUC: Paulus.

Rosenthal, R. W. (1999). O plantão de psicólogos no Instituto Sedes Sapientiae: uma proposta de atendimento aberto à comunidade. In M., Mahfoud. Plantão psicológico: Novos horizontes. São Paulo: Companhia Ilimitada.

Schimidt, M. L. S. (1999). Aconselhamento psicológico em instituição: algumas considerações sobre o serviço de aconselhamento psicológico do IPUSP. In H. P. T., Morato. (Org.), Aconselhamento psicológico centrado na pessoa: Novos desafios. (pp.91-106). São Paulo: Casa do Psicólogo.

Yehia, G. Y. (2004) Interlocuções entre o plantão psicológico e o psicodiagnóstico colaborativo: Dialogue between psychological duty and collaborative assessment. Campinas: Estudos de Psicologia, 21(1), p.65-72.

Recebido: 14/02/2008

Received: $02 / 14 / 2008$

Aprovado: 03/03/2008

Approved: 03/03/2008 